\title{
The Effect of Rotational Speed, Friction Duration, and Pressure on Tensile Strength of AISI 6061 Welding Joints
}

\author{
Dewi Puspitasari ${ }^{1}$, Poppy Puspitasari ${ }^{2 *}$, M. Rizka Gita Firmansyah ${ }^{3}$ and Solichin ${ }^{1}$ \\ ${ }^{I}$ Mechanical Engineering Department, Faculty of Engineering, University Technology Petronas, Malaysia \\ ${ }^{2}$ Department of Mechanical Engineering, Faculty of Engineering, Universitas Negeri Malang \\ 2 Center of Nano Research and Advanced Materials, Universitas Negeri Malang \\ *poppy@um.ac.id
}

\begin{abstract}
Electric arc welding with covered electrodes is ideally suited for flat plates. If this technique is employed for welding rigid bodies, the results would be of poor quality. One viable solution to weld rigid bodies is through friction welding. The study aimed to investigate the tensile strength of specimens subjected to friction welding with variations in rotational speed, friction time, and pressure and to examine the microstructure of friction welding joints. This research used the one-shot case study design and involved descriptive analysis. The descriptive analysis described the results of tensile testing and microstructure of welding joints. Results showed that the specimen subjected to a $2850 \mathrm{rpm}$ rotational speed, 60 -second friction duration, and $8 \mathrm{MPa}$ pressure had the highest tensile strength of $15.19 \mathrm{Kgf}$, whereas that rotated at $2850 \mathrm{rpm}$ under $8 \mathrm{MPa}$ pressure for 80 seconds had the lowest tensile strength, i.e. 12.25 Kgf. The photomicrographs showed that the friction welding joints underwent no phase change, but the refinement of $\mathrm{Mg}_{2} \mathrm{Si}$ particles occurred in the $\mathrm{Zpd}$ and $\mathrm{Zpl}$ zones. Also, the Zud zone consisted of the same form of $\mathrm{Mg}_{2} \mathrm{Si}$ particles as the untreated specimen.

Copyright (C) 2018Journal of Mechanical Engineering Science and Technology

All rights reserved
\end{abstract}

Keywords: Friction welding, tensile strength, microstructure

\section{Introduction}

Welding is an integral part of the growth and improvement of the industry, as it plays a major role in metal engineering and manufacturing. Welding with covered electrodes is widely used and more suitable for flat plates than rigid bodies. Rigid bodies are much more difficult to weld, and thus friction welding is a more reliable technique to use. In friction welding, metal is welded without melting it first. Instead, the joining process involves the rotating of one work piece against another at a constant pressure, which then generates heat caused by the friction between rubbing surfaces. Rotational speed, friction duration, and pressure are the determining variables in the quality of friction welding joints.

\section{Methodology}

This study was a type of pre-experimental design called the one-shot case study, in which a group of subjects were given a treatment and then observed. The independent variables involved in this study were variations in rotational speed, friction duration, and pressure, while the dependent variables were tensile strength resulted from friction welding. Data such as tensile test results and specimen microstructures after friction welding were analysed by descriptive data analysis. The standard for specimen tensile tesing used SNI 07-0371-1998 shown in Figure 1.

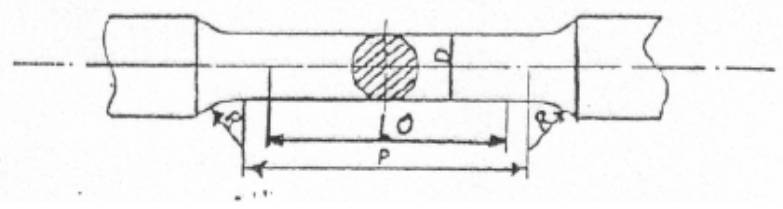

Fig. 1.Specimen of Tensile Testing (SNI 07-0371-1998) 
Table 1. Size of Tensile Test Specimen SNI 07-0371-1998

\begin{tabular}{cccc}
\hline Diameter (D) & Gauge Length (Lo) & Parallel Length (Lc) & Radius Shoulder (R) \\
\hline 12.5 & 50 & Approximately 60 & Maximum 15 \\
\hline
\end{tabular}

Table 2. Results of Elemental Composition Analysis (XRF)

\begin{tabular}{ccccccccccccc}
\hline Compound & $\mathbf{A l}$ & $\mathbf{M g}$ & $\mathbf{S i}$ & $\mathbf{K}$ & $\mathbf{C a}$ & $\mathbf{T i}$ & $\mathbf{C r}$ & $\mathbf{F e}$ & $\mathbf{B r}$ & $\mathbf{P}$ & $\mathbf{K}$ & $\mathbf{P r}$ \\
\hline Concentration $(\%)$ & 64,5 & 20 & 5,3 & 0,23 & 2,10 & 0,2 & 1,6 & 3,7 & 0,5 & 0,47 & 0,23 & 0,4 \\
\hline
\end{tabular}

Table 3. Results of Tensile Testing

\begin{tabular}{|c|c|c|}
\hline \multirow[t]{2}{*}{$\begin{array}{l}\text { Rotational } \\
\text { Speed }\end{array}$} & \multicolumn{2}{|c|}{$\begin{array}{c}\text { Tensile Strength of Al-Mg-Si at a friction pressure of } 8 \\
\qquad \mathrm{MPa}\end{array}$} \\
\hline & 60 seconds & 80 seconds \\
\hline \multirow[t]{3}{*}{$2850 \mathrm{Rpm}$} & 12.80 & 12.81 \\
\hline & 15.47 & 8.98 \\
\hline & 17,31 & 14.96 \\
\hline Mean & 15.19 & 12.25 \\
\hline \multirow[t]{3}{*}{$4000 \mathrm{Rpm}$} & 13.32 & 12.62 \\
\hline & 15.14 & 17.45 \\
\hline & 11.25 & 12.87 \\
\hline Mean & 13.23 & 14.31 \\
\hline
\end{tabular}

\section{Results and discussion}

\section{A. Elemental Composition Analysis}

Prior to friction welding, the composition of materials subjected to friction welding was determined using X-Ray Fluorescence (XRF) in Table 2.

\section{B. Tensile Testing}

Prior the tensile test results are presented in Table 3.

Table 3 shows the tensile strength resulted from variations in treatment. The treatment with a rotational speed of $2850 \mathrm{rpm}$, friction duration of 60 seconds, and a pressure of $8 \mathrm{MPa}$ produced a specimen with a tensile strength of $15.19 \mathrm{Kgf}$. The specimen rotated at $2850 \mathrm{rpm}$ for 80 seconds at 8 MPa had a tensile strength of $12.25 \mathrm{Kgf}$ shown in Figure 2. The specimen subjected to a $4000 \mathrm{rpm}$ rotational speed, 60-second friction duration, and $8 \mathrm{MPa}$ pressure had a tensile strength of 13.23. The specimen rotated at a $4000 \mathrm{rpm}$ speed under an $8 \mathrm{MPa}$ friction pressure for 80 seconds had a tensile strength of $14.31 \mathrm{Kgf}$.

Low rotational speeds and short friction durations produce high tensile strength. A specimen experiences a decrease in tensile strength when it rotates at a low speed for a longer time. It occurs because the maximum heat was generated during shorter friction duration. However, extending the duration of friction causes a decrease in temperature. In fact, these parameters affect significantly on the tensile strength of the friction welding joints [1].

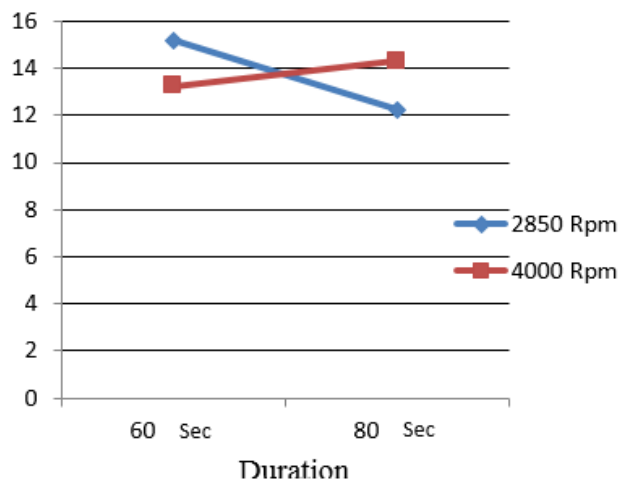

Fig. 2.Average Tensile Strength Resulted from Friction Welding 
Conversely, high rotation speeds coupled with longer friction durations tended to produce greater tensile strength. It happens by reason of the condition in which a specimen rotated at high speed for a short period of friction is unable to reach its peak temperature. On the other hand, a rotational motion set at high speed for a longer time is able to increase heat to the maximum temperature. However, a rise in friction duration may result in a decrease in tensile strength [2].

\section{Microstructure}

According to the ASM Handbook: Metallography and Microstructures, the aluminium matrix consists of dark particles, i.e. $\mathrm{Mg}_{2} \mathrm{Si}$ and grey particles, i.e. $\mathrm{Fe}_{3} \mathrm{SiAl}_{12} \mathrm{p}$ [3].

The Microstructureof the untreated specimen. Figure 3 shows the great distances between $\mathrm{Mg}_{2} \mathrm{Si}$ particles whose shape was almost spherical.

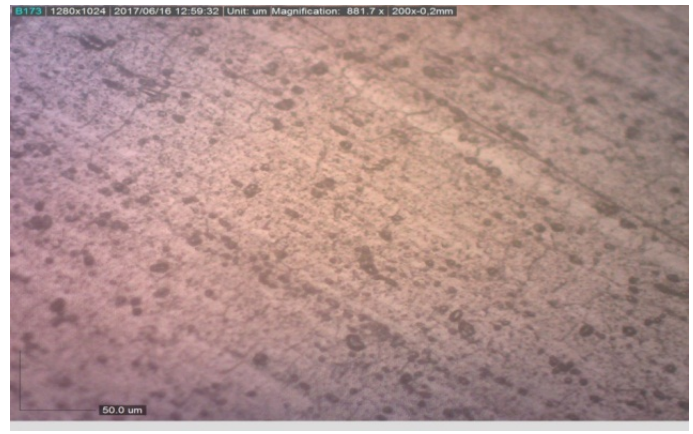

Fig. 3.Microstructure of Untreated Specimen
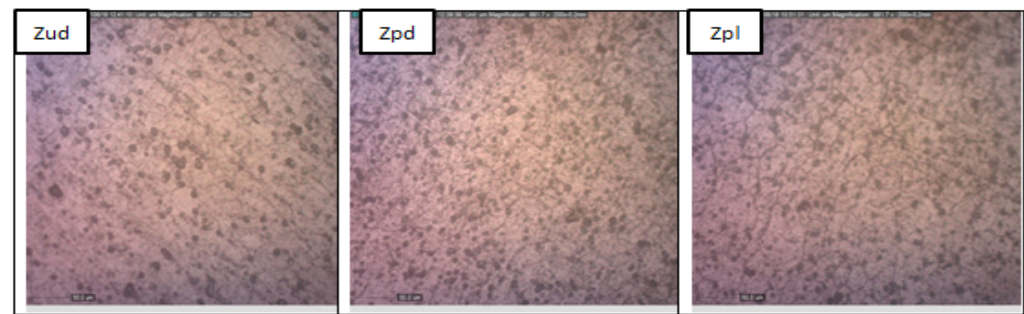

Fig. 4.Microstructure of Zud, Zpd (HAZ) and Zpl zones of the specimen rotated at $2850 \mathrm{rpm}$ and $8 \mathrm{MPa}$ for $60 \mathrm{~S}$
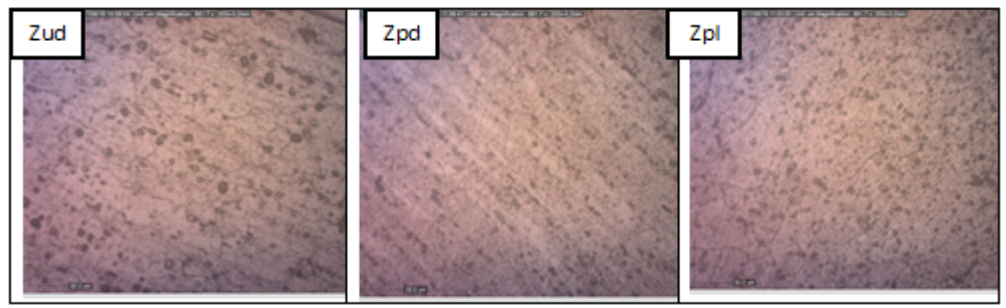

Fig. 5.Microstructure of Zud, Zpd (HAZ) and Zpl zones of the specimen rotated at $2850 \mathrm{rpm}$ and $8 \mathrm{MPa}$ for $80 \mathrm{~S}$

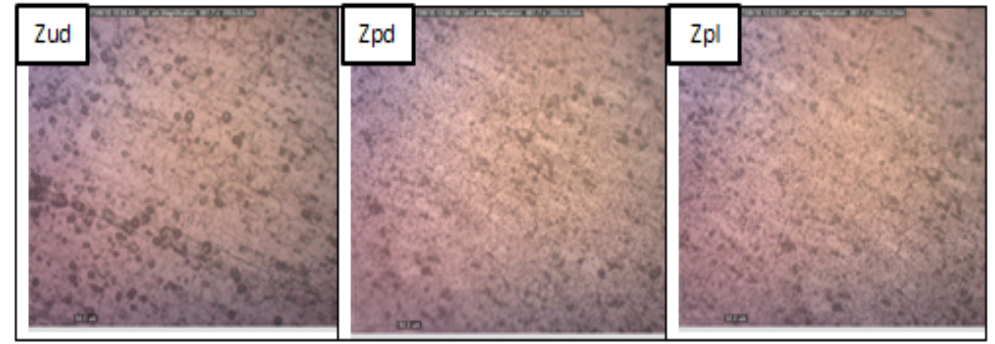

Fig. 6.Microstructure of Zud, Zpd (HAZ) and Zpl zones of the specimen rotated at $4000 \mathrm{rpm}$ and $8 \mathrm{MPa}$ for $60 \mathrm{~S}$ 


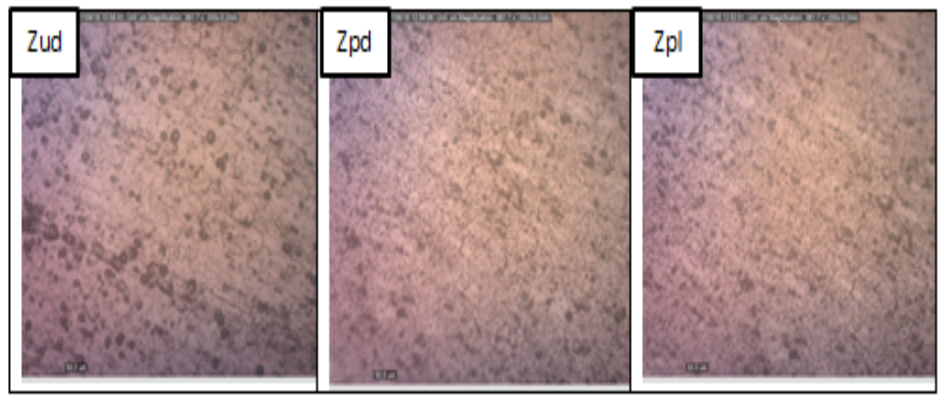

Fig. 7.Microstructure of Zud, Zpd (HAZ) and Zpl zones of the specimen rotated at $4000 \mathrm{rpm}$ and $8 \mathrm{MPa}$ for $80 \mathrm{~S}$

Friction welding only involves grain refinement of atoms without phase change because it does not use filler metal [4].Variations in treatment during the welding process results in varying microstructures in Zud, Zpd and Zpl zones [5]. As shown in Figure 4, 5, 6 and 7, the Zud zone had a large grain size while the grain size appeared in $\mathrm{Zpd}$ and a $\mathrm{Zpl}$ zone was small. It indicates that only grain refinement occurred (without phase change) in $\mathrm{Zpd}$ and $\mathrm{Zpl}$ zones because the welding process did not utilise filler metal [4]. Differences in Zud, Zpd and Zpl are owing to the heating process caused by friction and the forging process. The heating and forging processes lead to changes in microstructure [6].

The higher the temperature of the two rubbing surfaces is, the finer the grains will be. Variations in particle shape are due to varying temperature during the friction welding. In fact, each welding parameter has a considerable influence on microstructure, micro hardness, and strength [7].

\section{Conclusion}

Findings in this research have led to the following conclusions:

- The greatest tensile strength of $15.19 \mathrm{Kgf}$ was generated by the treatment involving a $2850 \mathrm{rpm}$ rotational speed, 60-second friction duration, and $8 \mathrm{MPa}$ pressure.

- The specimen subjected to a rotational speed of $2850 \mathrm{rpm}$, a friction duration of 80 seconds, and a pressure of $8 \mathrm{MPa}$ had the lowest tensile strength, i.e. $12.25 \mathrm{Kgf}$.

- The Zud zone and untreated specimen had the same microstructure.

- Structure refinement of Mg2Si occurred in Zpd and Zpl zones.

- The finer the Mg2Si particles was, the higher the tensile strength of friction welding joints would be.

- A large number of Mg2Si particles led to an increase in tensile strength.

\section{References}

[1] R. Kumar, R. Singh, I. P. S. Ahuja, A. Amendola, and R. Penna, "Friction welding for the manufacturing of PA6 and ABS structures reinforced with Fe particles," Composites Part B: Engineering, vol. 132, pp. 244-257, 2018.

[2] A. Dawood, S. Butt, G. Hussain, M. Siddiqui, A. Maqsood, and F. Zhang, "Thermal Model of Rotary Friction Welding for Similar and Dissimilar Metals," Metals, vol. 7, no. 6, p. 224, 2017.

[3] S. F.W and D. Dwilaksana, "Analysis of Mechanical Properties And Micro Structures Aluminum Alloys Al-Mg-Si Results Welding Friction Welding With Variation Speed Play," Rotor, vol. 7, no. 2, 2014.

[4] B. Sugito, A. D. Anggono, and D. Prasetyana, "Effect of Depth Pin (Depth Plung) Against the Strength of Laser Connection On Welding Strength AL 5083," in The 3rd Universty Research Coloquium 2016, 2016.

[5] S. Prasetyono and H. Subiyanto, "Effect of Friction Duration, Swipe Pressure and Forging Pressure Against Impact Strenght Direct Spindle Weld Connect on AISI 1045 Carbon Steel," Jurnal Sains \& Seni POMITS, vol. 1, no. 1, pp. 1-5, 2012. 
[6] B. L. Sanyoto, N. Husodo, S. B. Setyawati, and M. Murshid, "Application of Friction Welding (Friction Welding) Technology) In The Process Of Connecting Two Low Carbon Steel Steel Pipes," Jurnal Energi \& Manufaktur, vol. 5, 2012.

[7] M. B. Uday and M. N. A. Fauzi, "Joint properties of friction welded 6061 aluminum alloy/YSZ-alumina composite at low rotational speed," Materials \& Design, vol. 59, pp. 76-83, 2014. 